\title{
Features of Polymer-Cement Composite Formation for Innovative Construction Using Additive Technology
}

\author{
V.A. Poluektova, N.A. Shapovalov and Z.V. Stolyarova \\ Belgorod State Technological University, 308012 Belgorod, Russian Federation
}

\begin{abstract}
The creation of materials for additive technologies and managing their properties depends mainly on a deep and clear understanding of the processes of hydration and structure formation in disperse systems. This study describes the experience of study of composite polymer-cement material for 3D printing products and designs, peculiarities of structure formation of modified polymer-cement dispersions and their particular components. When researching, diffractograms of modified Portl and have been received and the kinetics of hydration process have been studied. The microstructure of composite material was also studied by means of scanning electron microscopy method. It has been proved that solidified polymer cement structure is represented by conglomeration of mutually penetrating mineral and organic constituents. So, crystallized coagulation structure is formed and it strengthens by polymeric componentin defective places of cement stone (pores, cracks), what leads to the formation of a more solid and elastic structure. Main recommendations were formulated and scientifically-grounded and should be taken into account when creating the polymer cement composites for 3D printing.
\end{abstract}

Key words: 3D printing, additive manufacturing, polymer cement composite, modifiers, superplasticizer, cross-linking

\section{INTRODUCTION}

Innovative direction in the construction industry is the use of 3-dimensional printing using a concrete with the help of additive technology. The development of these relatively new technologies will allow 3D construction method of concrete to be much cheaper and more effective to build unique buildings than traditional methods of construction. Development and study of new materials used in the construction of 3D printing are currently relevant due to the fact that many developers of building 3D printers are facing the problem of selection of materials. Fundamental concepts of industry ratio "design-material-technology" is not yet integrated in the construction sphere (Vatin et al., 2017). Normal concrete, based on cement does not meet the requirements for construction materials for building 3D printing (Hager et al., 2016). When designing material for 3D printing process it should be taken into account at least two conditions. Firstly, the force of adhesion between layers decreases with increasing of time interval between applying the next layer (Lloret et al., 2015). Secondly, the material must harden enough to bear the weight of subsequent layers without deformation. A comparison of these two constraints leads to a paradox: the time interval between two painted layers should be long enough to provide the necessary strength of layer but also rather short for maintenance of strong adhesive between layers (Le et al., 2012).

In our view, this problem can be solved by the development of composite material on the basis of two binders: mineral (binder of hydration hardening) and organic (polycondensation hardening) (Poluektova et al., 2016). Polymeric binder provides strength of adhesion between the layers and the necessary plastic strength can be achieved through the modification of cement system by superplasticizing additives due to reducing the water cement relation $(\mathrm{w} / \mathrm{c})$ mixture.

This study describes the experience of study of composite material based on polymer-cement fine-grained mixtures for building three-dimensional printing, peculiarities of formation of these compounds and their individual components.

\section{MATERIALSANDMETHODS}

Composite material for additive technologies is developed on the basis of two binders: organic and mineral. The basis of polymer-cement composite was mineral binder is Portland cement m 500 D0 (GOST 10178-85). Mineralogical and chemical compositions of used Portland cementsof different Russian producers are presented in Table 1.

Corresponding Author: V.A. Poluektova, Belgorod State Technological University, 308012 Belgorod, Russian Federation 
Table 1: The mineralogical and chemical composition of cements

The composition of cement, mass. (\%)

\begin{tabular}{|c|c|c|c|c|c|c|c|c|c|c|c|}
\hline \multirow[b]{2}{*}{$\begin{array}{l}\text { Type of cement } \\
\text { (specific surface) }\end{array}$} & \multicolumn{5}{|c|}{ Chemical composition } & \multicolumn{5}{|c|}{ Mineralogical composition } & \multirow[b]{2}{*}{$\begin{array}{c}\text { Free } \\
\text { calciumoxide }\end{array}$} \\
\hline & $\mathrm{SiO}_{2}$ & $\mathrm{Al}_{2} \mathrm{O}_{3}$ & $\mathrm{Fe}_{2} \mathrm{O}_{3}$ & $\mathrm{CaO}$ & $\mathrm{MgO}$ & $\mathrm{SO}_{3}$ & $\mathrm{C}_{3} \mathrm{~S}$ & $\mathrm{C}_{2} \mathrm{~S}$ & $\mathrm{C}_{3} \mathrm{~A}$ & $\mathrm{C}_{4} \mathrm{AF}$ & \\
\hline Belgorod $\left(354 \mathrm{~m}^{2} / \mathrm{kg}\right)$ & 22.52 & 5.00 & 4.38 & 66.31 & 0.66 & 0.20 & 64.0 & 16.0 & 4.0 & 13.0 & 0.37 \\
\hline Oskol $\left(360 \mathrm{~m}^{2} / \mathrm{kg}\right)$ & 20.28 & 5.53 & 4.07 & 64.51 & 0.74 & 2.49 & 63.7 & 12.0 & 8.5 & 12.8 & - \\
\hline Novorossiysk $\left(376 \mathrm{~m}^{2} / \mathrm{kg}\right)$ & 21.87 & 5.18 & 4.39 & 66.12 & 0.79 & 0.50 & 62.0 & 15.0 & 7.0 & 14.0 & - \\
\hline Voronezh $\left(220 \mathrm{~m}^{2} / \mathrm{kg}\right)$ & 20.79 & 5.06 & 4.91 & 63.17 & 0.80 & 0.15 & 58.5 & 13.1 & 6.5 & 11.8 & - \\
\hline
\end{tabular}

As an organic component, the polyvinyl acetate dispersion has been used (PVAD, the coarse homopolymerpolyvinylacetate dispersion, according to ГOCT 18992-80). It is a homogeneous mixture of an aqueous dispersion with a solids of polyvinyl acetate not $>51 \%$. The amount of dispersion PVAD was taken into account when calculating the water cement ratio $(\mathrm{w} / \mathrm{c})$. Choice of PVAD for the developed composition is due to a good combination with cement according to data (Popov, 1987) and the lack of clear signs of coagulation system.

For the modification of the surface of the particles of polymer mineral mixture with a view to obtain the required plastic layer strength and timing management setting we used phloroglucinol modifier designed for mineral dispersion according to GOST 24211-2008 that is superplasticizer and high range water reducer supplement (Shapovalov and Poluektova, 2016). The concentration of additive modifier $\mathrm{Cm}$ was accounted apart of a dry substance of the mass of mineral binder.

As a small placeholder it was used the sand for construction works with the module size $\mathrm{Mk}=2.0 \div 2.5$ (average) according to GOST 8736-2014.

The study of the phase composition and hydration of Portland cement processes was conducted by using $\mathrm{X}$-Ray Analysis (XRA). The X-ray diffraction analysis of samples of the modified cement stone at the age of 2, 7, 28 days was conductedon the diffractometer DRON-3 with $\mathrm{SiK} \alpha$-radiation and nickel filter. Shooting mode: voltage $35 \mathrm{kV}$, anode current of $12 \mathrm{Ma}$. The intensity of the diffraction lines was defined as the height of the peak above the mean line of the background. Based on the results of measurements of the intensity of the reflections the calibration graphs were built where on the ordinate axis was postponed mass fraction of a corresponding mineral in the reference mixture, expressed in $\%$ and the abscissa is the magnitude of the ratio of intensity of analytical lines of the mineral and the standard fluorite. The study of microstructure of polymer cement samples were conducted by a method of Scanning Electron Microscopy (SEM) based on images on a high-resolution microscope TESCAN MIRA 3 LMU.

\section{RESULTS AND DISCUSSION}

When developing composite materials, it is important that each component retains its properties. So, the first requirement to the polymer cement composition was chemical indifference of components, i.e., cement and hydration products should not chemically interact with the polymer dispersion (Korneyev, 2002).

A number of studies have shown that a mutual influence of polymeric and mineral binders in the polyvinyl acetate system takes place but their hardening is going independently. Hydration and chemical binding of water and cement begins instantly after mixing the dry mix with water. Hardening of polymer dispersions with polymeric film formation starts when the system is dehydrated due to chemical absorption of water with cement and because of drying. Polymer films (membranes) are involved in cement gel, resulting in complex organic mineral conglomerate.

Research of various polymer cement compositions showed that initially it was formed a coagulation structure without chemical bonds between mineral and organic component. The interaction was adsorptive in nature, based on weak hydrogen and van der Waals contacts. Agglomeration of particles of PVAD during solidification of composite mixture occurs only at temperatures above the minimum film formation temperature (ICC). It is known that the PVAD are plastifisized to improve the coalescence of the polymer particles. The glass transition temperature of polyvinyl acetate is $28^{\circ} \mathrm{C}$, and ICC dispersion PVA is about $5^{\circ} \mathrm{Cat} \mathrm{pH}=4$. However, at $\mathrm{pH}=5.5 \mathrm{ICC}=20^{\circ} \mathrm{C}$ and at $\mathrm{pH}=6 \mathrm{ICC}=30^{\circ} \mathrm{C}$, i.e., $\mathrm{ICC}$ of PVAD depends on the $\mathrm{pH}$ dispersion. This is due to the fact that each particle of poly vinyl acetate is surrounded by polyvinyl alcohol molecules which solvate ability depends on the $\mathrm{pH}$ dispersion. In the process of mixing the PVAD with Portland cement comes the increasing of $\mathrm{pH}$ systemand temperature rise by heat dissipation, i.e., the conditions for film formation in polymercement composite materialaremet. However, for cement hardening it is required $100 \%$ relative air humidity or even water environment and for convergence of polymer particles, subsequent agglomeration and the formation of polymer film the dehydration system is necessary, i.e., dry 
hardening conditions are required (low humidity). On this basis, the optimal thermo damp mode for polymer cement mortar mixtures hardening is a combined mode: to ensure moist curing at early stages (in air with $95-100 \%$ relative humidity) for 1-2 days, after which the hardening in air with a relative humidity of $\sim 50 \%$ (Korneyev, 2002). When creating products and installations by using three dimensional printing the hardening mode of polymer cement materials is more acceptable than the hardening regime of ordinary concrete.

When you create a polymer-cement material with the appropriate properties for the additive technology by modifying it is necessary to take into account that the adsorption of molecules of superplasticizers on beans of cement and the appearance of polymeric membranes are capable to change the kinetics of the hydration of clinker minerals in the direction of slowing down. They have the strong influence on hydration of most content $\mathrm{C}_{3} \mathrm{~S}$, phase, as well as the phase of $\mathrm{C}_{3} \mathrm{~S}$ which has the highest rate of hydration in primary terms of hardening (Brykov, 2008).

The influence of phloroglucinol furfural modifier on hydration processes of polymer cement compositions was studied at the cement stone, obtained in different types of cement. In the course of the study, there were changes in the structure of the cement stone, gained in the early stages of hardening ( 2 and 7 days) and on the 28th days. Dosage of modifiers was $0.1-0.4 \%$ on dry substance of weight of cement. For a comparative analysis the control samples were also made of a cement stone without modifiers and with commonly used in Russia superplasticizer $\mathrm{C}-3$ on the base of naphthalene formaldehyde sulfonated oligomers.

Studies were conducted with the help of X-Ray Analysis (XRA). The content of the alite phase which is a solid solution on the basis of tricalcium $\mathrm{C}_{3} \mathrm{~S}$ silicate in studied cement were ranged from $58-64 \%$. Belit (solid solution on the base of dicalcium silicate $\mathrm{C}_{2} \mathrm{~S}$ ) is the second phase, the contents of which correspond to $12-16 \%$. The phases of tricalcium aluminate $\left(\mathrm{C}_{3} \mathrm{~A}\right)$ and four calcium alumoferrite $\left(\mathrm{C}_{4} \mathrm{AF}\right)$ were presented in small numbers. Hydraulic characteristics of Portland cement determine, first of all, the presence of $\mathrm{C}_{3} \mathrm{~S}$ and $\mathrm{C}_{2} \mathrm{~S}$ phases (Fig. 1). It is known that at $70, \ldots, 80 \%$ of properties of cementare defined by alite which is similar by the basic properties to Portland cement (water requirement, adhesive behavior). Belit provides later cement hardening from a few months to several years.

The products of reaction of alite and belit with water is portlandite $\left(\mathrm{Ca}(\mathrm{OH})_{2}\right)$ and almost amorphous calcium hydrosilicate $\mathrm{C}-\mathrm{S}-\mathrm{H}$, possessing solid gel properties.

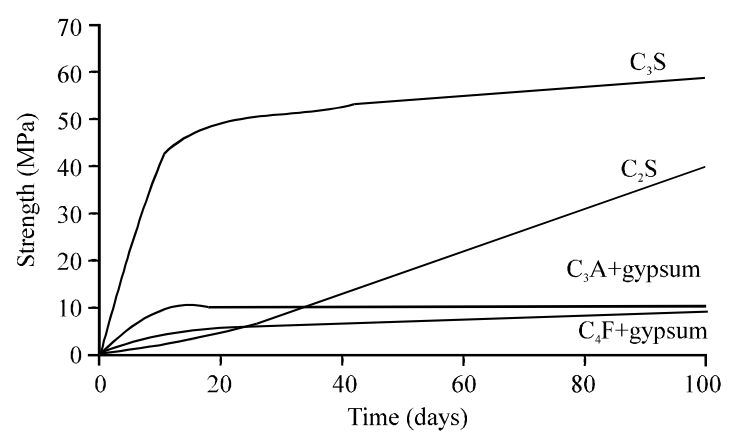

Fig. 1: Hydraulic activity of various minerals of Portland clinker

The study of cement hydration kinetics of a control sample showed that on the second day of hardening from the moment of mixing with water the reflexes on cement stone were observed corresponding to source phases of Portland cement: alite and belit and low-intensity portlandite reflexes as well. At the same time, on the diffractograms there were intensive reflexes in the field of interplanar distances $(\mathrm{d})=14.7-8.0 \AA$ relevant significant quantities of poorly crystallized phases and in area (d) = 3.3-2,4 $\AA$ cement for C-S-H (I) gel (Chen et al., 2004), the volume of which defines the strength characteristics of stone (Shoshin and Timokhin, 2007).

At the control samples of the age of 7 and 28 days it is seen there distribution of intensities of the reflections of weakly crystallized phases: intensity of reflex gel phase decreases $(\mathrm{d})=14.7-8,0 \AA$ with simultaneous increase in the intensity of the reflections of portlandite $(\mathrm{d})=4.94 \AA$ and cement $\mathrm{CSH}(\mathrm{I}) \mathrm{d}=2.63 \AA$. A similar pattern was observed in the research of Shoshin and Bylinkina (2012). Quantitative assessment of changes in the relative intensities of these reflections confirms researchers assumption that reflex in area $\mathrm{d}=14.7-8,0 \AA$ corresponds to primary highly hydratedgel form which, over time, thickening, transfers to the main form of CSH (I) gel with reflex in area $d=2.63 \AA$.

In the presence of phloroglucinol furfural modifier the general nature of hardening kinetics is retained. However, on the second day of hydration on diffractograms the intensity of reflexes of poorly crystallized phases decreased under the same diffraction angles. But on 28 th days the typeofa modified spectrum of the sample (Fig. 2b) is significantly different from the control sample (Fig. 2a). On diffractograms for samples on the Oskol PC 500 D0 with phloroglucinol furfural modifier in quantities of $0.1 \%$ there is a noticeably greater intensity of the hydration of clinker minerals. This is proved by the clear reflections of portlandite $\mathrm{Ca}(\mathrm{OH})_{2}$ (reflex $4.94 \AA$ ) and C-S-H (I) gel with reflex in area $\mathrm{d}=2.63 \AA$. Reflexes in the 

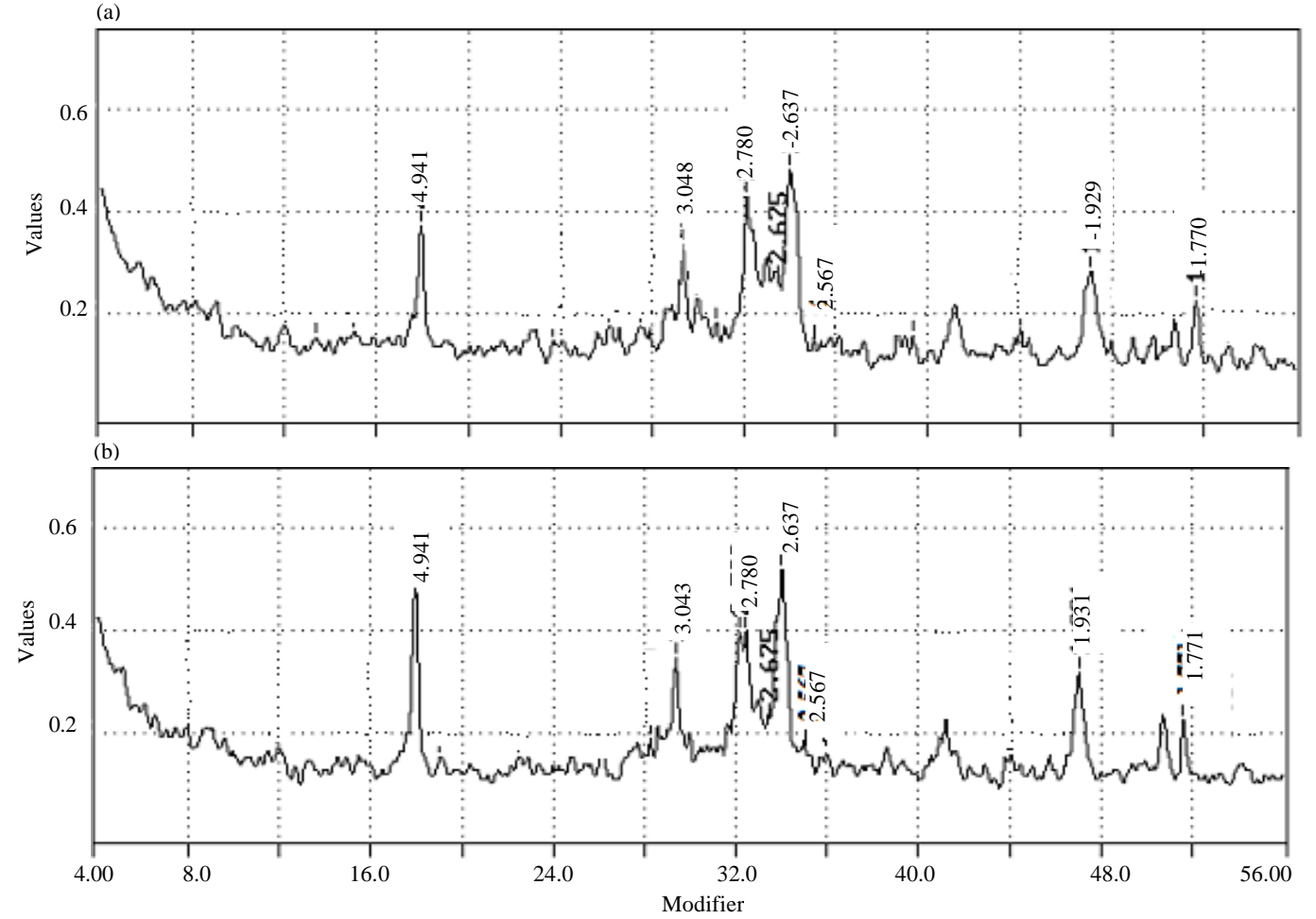

Fig. 2: The influence of modifier on the phase transition of a cement stone at the Oskolsky PC 500 D0: a) Control and b) With a $0.1 \%$ modifier

Table 2: Influence of the modifier on the relative intensity of reflexes on diffractograms of different types of cement

\begin{tabular}{|c|c|c|c|c|c|c|c|}
\hline \multirow[b]{3}{*}{ Type of cement } & \multirow[b]{3}{*}{$\begin{array}{l}\text { The modifier } \\
\text { concentrationn } \mathrm{C}_{m}(\%)\end{array}$} & \multicolumn{6}{|c|}{ The intensity of the reflex } \\
\hline & & \multicolumn{2}{|c|}{ Hydration products } & \multicolumn{2}{|c|}{ The original clinker minerals } & \multicolumn{2}{|c|}{$\begin{array}{l}\text { Relationship intensity of } \\
\text { analytical reflexes phases }\end{array}$} \\
\hline & & $\begin{array}{l}\mathrm{Ca}(\mathrm{OH})_{2} \\
4.94 \AA\end{array}$ & $\begin{array}{l}\mathrm{C}-\mathrm{S}-\mathrm{H}(\mathrm{I}) \\
2.63 \AA \\
\end{array}$ & $\begin{array}{l}\mathrm{C}_{3} \mathrm{~S} \\
3.04 \AA\end{array}$ & $\begin{array}{l}\mathrm{C}_{2} \mathrm{~S} \\
2.78 \AA \\
\end{array}$ & $\begin{array}{l}\mathrm{Ca}(\mathrm{OH})_{2} / \\
\mathrm{AБ} \Phi\end{array}$ & $\begin{array}{l}\mathrm{C}-\mathrm{S}-\mathrm{H} \\
\text { (I)/AБ } \Phi \\
\end{array}$ \\
\hline$\overline{1}$ & 2.0 & 3 & 4 & 5 & 6 & 7.00 & 8.00 \\
\hline \multirow[t]{5}{*}{ OskolPC-500 D } & 0.0 & 121 & 178 & 109 & 154 & 0.46 & 0.68 \\
\hline & 0.1 & 176 & 196 & 118 & 140 & 0.68 & 0.75 \\
\hline & 0.2 & 152 & 162 & 120 & 130 & 0.60 & 0.68 \\
\hline & 0.3 & 150 & 192 & 110 & 166 & 0.54 & 0.70 \\
\hline & 0.4 & 105 & 159 & 132 & 204 & 0.31 & 0.47 \\
\hline \multirow{5}{*}{ Novorossiysk PC 500 D0 } & - & 155 & 200 & 101 & 176 & 0.56 & 0.72 \\
\hline & 0.1 & 125 & 168 & 117 & 168 & 0.44 & 0.58 \\
\hline & 0.2 & 125 & 178 & 101 & 194 & 0.42 & 0.60 \\
\hline & 0.3 & 149 & 165 & 115 & 192 & 0.48 & 0.54 \\
\hline & 0.4 & 99 & 154 & 122 & 216 & 0.29 & 0.45 \\
\hline 1 & 2.0 & 3 & 4 & 5 & 6 & 7.0 & 8.00 \\
\hline \multirow[t]{5}{*}{ TeploozerskyPC Do } & - & 121 & 179 & 91 & 145 & 0.51 & 0.76 \\
\hline & 0.1 & 166 & 186 & 88 & 165 & 0.66 & 0.74 \\
\hline & 0.2 & 180 & 200 & 88 & 171 & 0.69 & 0.77 \\
\hline & 0.3 & 171 & 195 & 113 & 163 & 0.61 & 0.71 \\
\hline & 0.4 & 133 & 176 & 120 & 219 & 0.39 & 0.52 \\
\hline
\end{tabular}

area of 3.04 and $2.78 \AA$ describing alit $\mathrm{C}_{3} \mathrm{~S}$ and belit $\mathrm{C}_{2} \mathrm{~S}$, on radiographs of cement with the modifier are expressed less intensely compared with similar lines of control sample, this suggests that the modifier helps to accelerate the hydration of these clinker minerals.

With the further increase in concentration of phloroglucinol furfural modifier (Fig. 3) the intensity of the reflection of portlandite $\mathrm{Ca}(\mathrm{OH})_{2}(4.94 \AA)$ gradually decreases and the intensity of the reflection of alite-belit phases (ABP): alite $\mathrm{C}_{3} \mathrm{~S}(3.04 \AA)$, belit $\mathrm{C}_{2} \mathrm{~S}(2.78 \AA)$ and cement gel C-S-H (I) $(2.63 \AA)$ grows and on $0.3-0.4 \%$ content in cement stone of most types of cement (Table 2) is compared to the value of the control sample. 


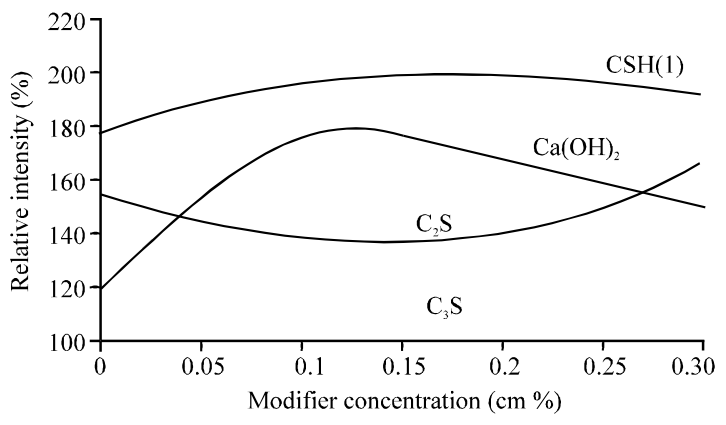

Fig. 3: The impact of the phloroglucinol furfural modifier on the relative intensity of the fundamental reflexes on diffractogram of the modified Oskolcement PC 500 D0

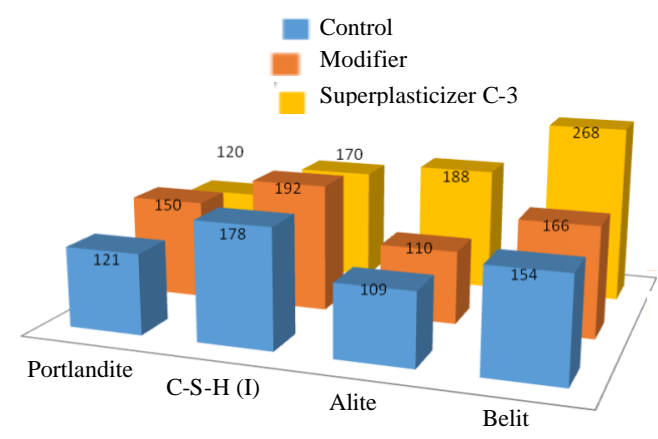

Fig. 4: The relative intensity of the reflexes of the basic clinker minerals and hydration products of Belgorod-PC 500 D0 in the presence of phloroglucinol furfural modifier and superplasticizer $\mathrm{C}-3(\mathrm{Cm}=0.3 \%)$

Figure 3 shows that the phloroglucinol furfural modifier in dosages of up to $0.2 \%$ from the weight of cement accelerates hydration processes of $\mathrm{C}_{3} \mathrm{~S}$ and $\mathrm{C}_{2} \mathrm{~S}$, but the influence of synthesized oligomers on hydration of belit is more meaningful. This represents an acceleration of a strength of modified cement stone.

Comparative characteristic of impact of phloroglucinol furfural modifier and naphthalene formaldehyde superplasticizer c-3 on hydration processes of Belgorod cement PC 500 D0 on values relative to intensitiesof reflexes of the main clinker minerals and hydration products is presented as 3-D histogram (Fig. 4).

Modifier concentration was chosen at $0.3 \%$ from the weight of cement for greater visibility of differences of negative effects of additives on the processes of hydration because up to $0.2 \%$ phloroglucinol furfural modifier has a positive effect. With that the $\mathrm{C}-3$ has a lower activity, so the introduction of the concentrations of $>0.3 \%$ is not effective.

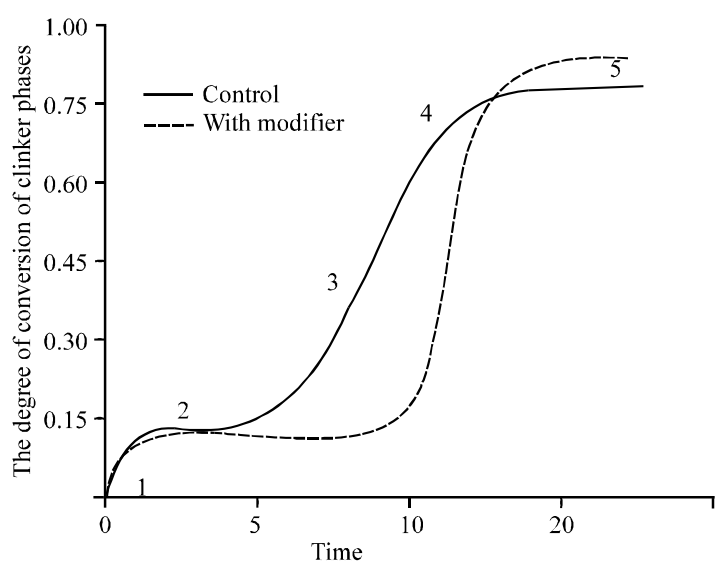

Fig. 5: Periods of hydration of Portland cement: 1) Initial interaction with water (the initial period); 2) Induction period; 3) The period of acceleration; 4) Period of deceleration and 5) period of slow interaction

The histogram shows that in the control sample and the sample with phloroglucinol furfural modifier approximately $70 \%$ of $\mathrm{C}_{3} \mathrm{~S}$ reacted during 28 days and C-3 significantly demonstrated the process of hydration of the basic clinker minerals.

A number of data obtained by XR analysis showed that the hydration develops unevenly over time. Kinetic curve of the hydration of Portland cement can be divided into five periods (Fig. 5):

Curves presented in Fig. 5 are average for different cements. The introduction of phloroglucinol furfural modifier extends the induction period during which the germs of neoplasms are formed, and reduces the period of acceleration which is associated with the dramatic increase in the surface between interacting phases because of the advent of a greater number of smaller centers of crystallization due peptizing action of the modifier (Poluektova et al., 2012).

Researches have shown that studied modifier, like many superplastisizing supplements, slow down the process of setting, i.e., increase the induction time of hardening of Portland cement. However, the period 3, period of strength accelerating is dramatically enhanced with the optimal dosages of supplements that are not typical for widely used superplastisizer C-3.

Study of influence of PVAD on cross-linking mineral binders revealed that large quantities of polymer $(\mathrm{p} / \mathrm{c}=0.2) 2$ times lengthened induction period of hardening which is comparable to the influence of modifier. With the decrease of $w / c$ of modified mixture for obtaining the required plasticity of composite the 
(a)
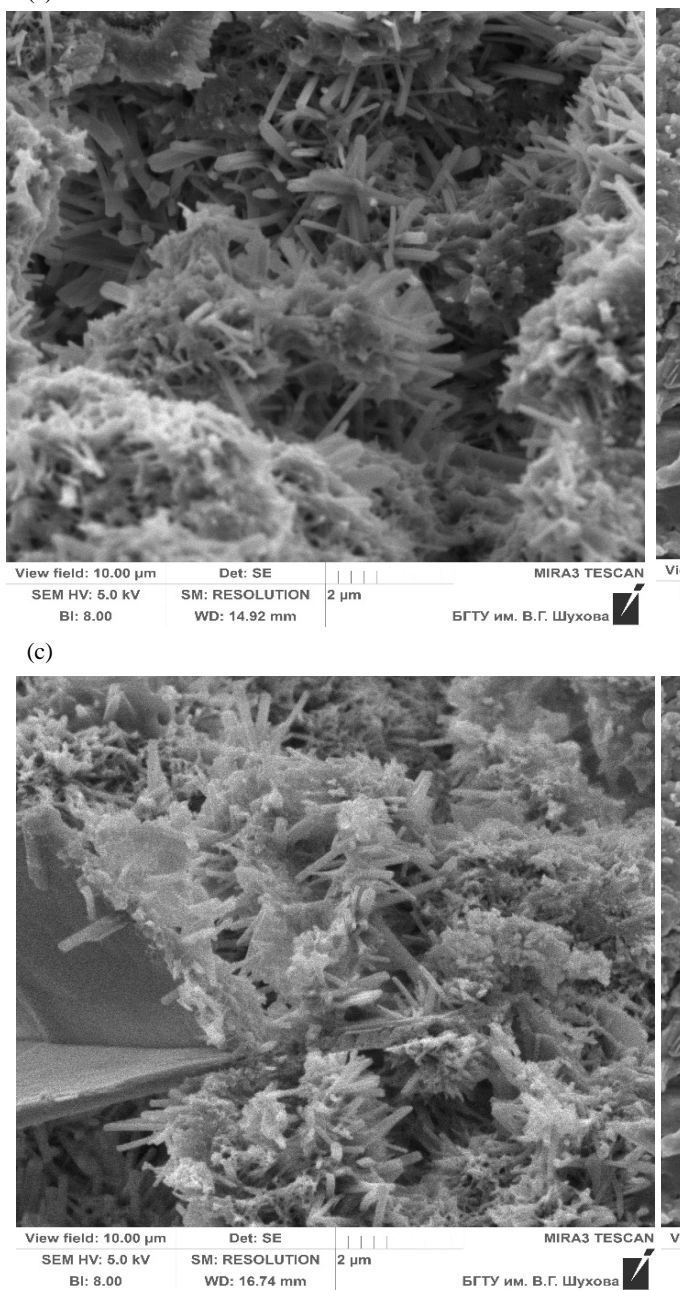

(b)

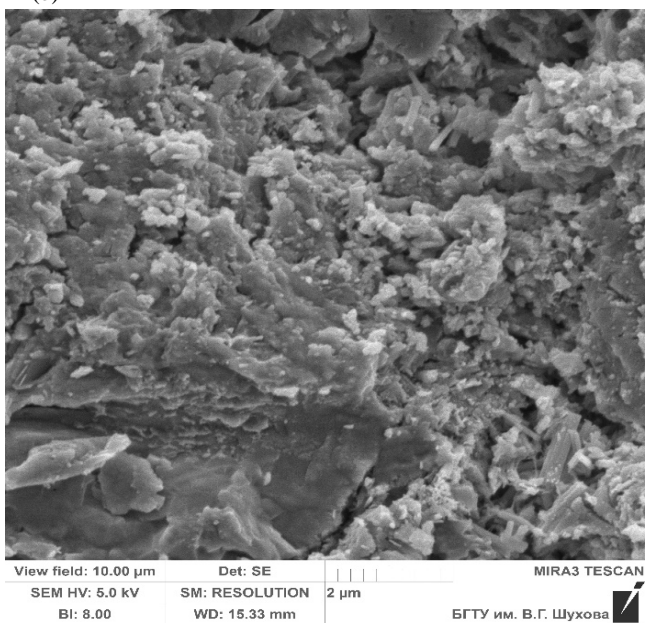

(d)

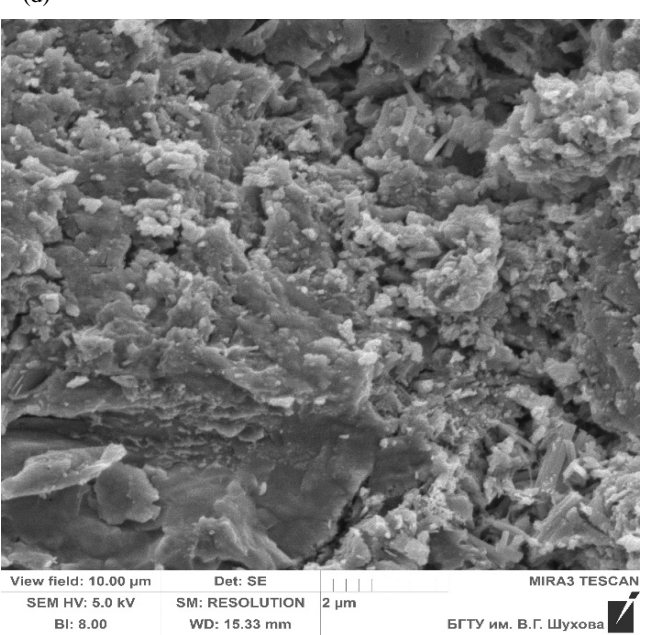

Fig. 6: Microphotos of SEM polymer-cement stone of Voronezh PC $500 \mathrm{D} 0 \mathrm{w} / \mathrm{c}=0.4 ; \mathrm{a}) \mathrm{p} / \mathrm{c}=0.075 ; \mathrm{b}) \mathrm{p} / \mathrm{c}=0.1 ; \mathrm{c}) \mathrm{p} / \mathrm{c}$ $=0.15$ and $\mathrm{d}) \mathrm{p} / \mathrm{c}=0.2$

induction period is greatly reduced and reaches the time of control sample while maintaining intensity period of acceleration.

Study of microstructure of polymer-cement stone using the method of Scanning Electron Microscopy (SEM) is presented in Fig. 6.

The micro photos show that solidified polymercement structure is represented by a conglomeration of mutually penetrating mineral and organic constituents. When the values of $\mathrm{p} /$ care under 0.2 the hydrate phases form crystalized coagulate structure which is strengthened by the polymer component in defective places of a cement stone (pores, cracks) which leads to the formation of a more solid and elastic structure with optimal $\mathrm{p} / \mathrm{c}=0.1$. With the increase of polymer component over $20 \%$ $(\mathrm{p} / \mathrm{c}=0.2)$ a continuous polymer net is formed in which Portland cement and its hydration products are distributed discretely and essentially, under the formation of organic mineral matrix act as a mineral filler. There has also been a significant influence of the polymer on the kinetics of hydration of mineral binder and speed curing. The obtained data do not contradict other research scientists.

\section{CONCLUSION}

The creation of materials for additive technologies and managing their properties depends mainly on a deep and clear understanding of the processes of hydration and structure formation in disperse systems. This research gives a thorough study of the phenomena observed at different stages of the processes of structuration of modified polymer-cement composite material and its components. Domains of polymeric binder 
bind organic mineral components of the structure through high adhesive properties, filling the pores and fixing defective places. When this polymer film on the surface of the material provides the adhesion between the layers necessary for additive technologies. And the phloroglucinol furfural modifier provides the necessary plastic layer strength due to decrease $\mathrm{p} / \mathrm{c}$. The hardening of polymercement system leaks due to the two independent processes: hardening of modified cement system and hardening of the polymer.

\section{RECOMMENDATIONS}

The general requirements when obtaining composite materials for additive technologies are: composition of the material on the basis of two binders of hydration and polycondensation hardening, mineral binder and polymer indifference; modification of the surface of the particles to regulate properties of dispersions, dry or combined conditions of hardening, formation of organic mineral structure with continuous cement matrix, consisting of products of hydration of cement while the polymer (organic) part of the system should be distributed in the cement matrix in the form of discrete entities.

\section{ACKNOWLEDGEMENT}

The study was prepared within a development program of the Base University on the basis of BSTU named after V.G. Shukhov.

\section{REFERENCES}

Brykov, A.S., 2008. Hydration of portland cement: A tutorial. Master Thesis, Saint Petersburg State Institute of Technology, Saint Petersburg, Russia.

Chen, J.J., J.J. Thomas, H.F. Taylor and H.M. Jennings, 2004. Solubility and structure of calcium silicate hydrate. Cem. Concr. Res., 34: 1499-1519.
Hager, I., A. Golonka and R. Putanowicz, 2016. 3D printing of buildings and building components as the future of sustainable construction?. Procedia Eng., 151: 292-299.

Korneyev, V.I., 2002. About the mechanisms of action of functional additives in hydration and hardening of dry building mixes. Bombay mix, India, Gujarat. http://www.baltimix.ru/confer/confer_archive/.

Le, T.T., S.A. Austin, S. Lim, R.A. Buswell and R. Law et al., 2012. Hardened properties of high-performance printing concrete. Cem. Concr. Res., 42: 558-566.

Lloret, E., A.R. Shahab, M. Linus, R.J. Flatt and F. Gramazio et al., 2015. Complex concrete structures: Merging existing casting techniques with digital fabrication. Comput. Aided Des., 60: 40-49.

Poluektova, V.A., N.A. Shapovalov and E.I. Evtushenko, 2016. Nano-modified polymer solution for additive technologies. Intl. J. Pharm. Technol., 8: 24930-24937.

Poluektova, V.A., A.A. Slyusar and N.A. Shapovalov, 2012. Superplasticizer Based on Phloroglucinol Furfural Oligomers for Water Mineral Suspensions: Monograph. Belgorod State Technological University named after V.G. Shukhov, Belgorod, Russia, Pages: 108.

Shapovalov, N.A. and V.A. Poluektova, 2016. Plasticizing Additives in Concrete: Monograph. Belgorod State Technological University named after V.G. Shukhov, Belgorod, Russia, Pages: 128.

Shoshin, E.A. and D.K. Timokhin, 2007. Effect of organic additives on crystallization character of cement gel: Advanced materials and technologies in modern construction. Master Thesis, Novosibirsk State Agrarian University, Novosibirsk, Russia.

Shoshin, E.A. and N.N. Bylinkina, 2012. Structure formation of cement stone in the presence of isomeric carbohydrates. Bull. SSTU., 3: 230-236.

Vatin, N.I., L.I. Chumadova, I.S. Goncharov, V.V. Zykova and A.N. Karpenya et al., 2017. 3D printing in construction. Constr. Unique Build., 1: 27-46. 